\title{
FLIPPING THE CLASSROOM TO TEACH THE EVALUATION OF RESEARCH ARTICLES AND THE DEVELOPMENT OF SCIENTIFIC LITERACY
}

\author{
Pamela Monaghan-Geernaert, Northern State University
}

\begin{abstract}
Scientific literacy is a key skill for college students. Flipped classroom techniques provide useful tools for students to learn material outside of the classroom to be applied during class time. In this study, students were assigned homework that entailed watching two video podcasts that explained the process for finding and reading peer-reviewed journal articles. Students then completed a survey corresponding to each video podcast asking about the effectiveness of the video podcast and their satisfaction with the perceived knowledge and skills they learned. In class, students worked in groups to practice the skills taught in the video. One hundred and six students completed both surveys. The results indicate that the students found the video podcasts very helpful in finding and reading the articles (89\% Finding, 92\% Reading). The students believed that watching the video podcasts would help them complete the in-class assignment (92\%), that the information would be useful for other classes (90\%), and that they preferred watching (and rewatching) the video podcasts on their own time instead of during class time (52\%). The flipped classroom methodologies, specifically video podcasts, provide a formative tool for delivering visual instruction of how students can acquire skills in scientific literacy.
\end{abstract}

Keywords: flipped classroom; pedagogy scientific literacy

\section{INTRODUCTION}

Scientific literacy has been defined in many ways, ranging from specific knowledge of scientific facts to a more general epistemology of learning about the world. The summative work by Norris and Phillips (2003) is among the more comprehensive analyses of the various definitions of scientific literacy. In their analysis, most of the definitions of scientific literacy were shown to contain four components:

a) knowing what counts as science and how science differs from nonscience;

b) having the knowledge needed for participating in science-related social issues;

c) knowing the risks and benefits of science; and

d) being able to think critically about science.

Despite the breadth of definitions, scientific literacy is deemed important in most $\mathrm{K}-12$ curriculum and therefore argued to be equally important in postsecondary education (Smith, Loughran, Berry, \& Dimitrakopoulos, 2012). Ensuring that students are competent in these four areas is a difficult task. This study incorporates a pedagogical methodology, specifically a flipped classroom experience, that utilizes video podcasts to address some of the components outlined by Norris and Phillips.

The National Academies of Science, Engineering, and Math (NASEM) developed the National Science Education Standards with a focus on defining the scope of scientific literacy and providing strategies for implementing it in the education curriculum (National Research Council, 1996). The goal of having scientifically literate students is to create a population that can make rationally informed decisions about the world. This population can effectively research information using appropriate searching techniques and distinguish valid sources of information from other sources (e.g., market or politically driven) 
(Park, Pearson, \& Richardson, 2017). Furthermore, scientifically literate individuals can read and comprehend articles about science and nature and critically evaluate the validity of the claims and conclusions made by researchers (Holbrook \& Rannikmae, 2007).

Ideally, scientific literate individuals use their knowledge and skills to participate in the democratic process by referencing science data for local, state, and national policy decisions (Yacoubian, 2018). Education at the college level needs to build on the material developed by NASEM that is taught in $\mathrm{K}-12$ and expand it to further challenge older students. The National Science Education Standards clearly outline a process for creating a scientifically literate student in the K-12 education curriculum. In college, General Education requirements are designed to ensure that students undertake a broad spectrum of learning opportunities; however, there is no equivalent criteria like the National Science Education Standards in postsecondary schools. Higher education provides opportunities for students to delve into topics and majors with increased focus, but it does not guarantee that the scientific literacy skills learned throughout $\mathrm{K}-12$ will be reinforced and built upon as students become adults (McGeough \& Rudick, 2018). An important opportunity is created for higher education teachers to rise to the challenge of incorporating assignments that reiterate and build on past skills regarding the acquisition and evaluation of scientific knowledge (Stark, Kintz, Pestorious, \& Teriba, 2018).

Teaching scientific literacy can be accomplished through several techniques. One such technique is the flipped classroom. The general concept of a flipped classroom may consist of students watching video podcasts on their own time and then coming to class with the knowledge from the video podcast to complete related activities in class (Horn, 2013). Unlike traditional classrooms where students complete homework on their own without help, the advantage of a flipped classroom is that students have direct access to the instructor while they are completing the assignments (Tucker, 2014). The flipped classroom empowers students and allows them to be in the driver's seat of their learning experience. Learning can be defined as the acquisition of knowledge or skills through experience, study, or by being taught. Hence, the flipped classroom is ideal for creating a learning environment for the students. The advantage of the flipped classroom is that students can learn the material at their own pace (Abeysekera \& Dawson, 2014). For example, if video podcasts are used, students can rewind or fast forward through sections that are either challenging or familiar, thus allowing students to customize their learning experience.

Flipped classroom assignments are helpful to instructors in gauging the students' understanding of concepts and their application of skills in real time in the classroom instead of waiting potentially weeks for an exam (Chen \& Summer, 2015). Given this, classroom time can be used to immediately reinforce what was taught in the podcast, and instructors become responsible for engaging students with active learning in the classroom. Students in a flipped classroom are no longer passive learners and instructors are no longer uncertain whether students are comprehending the material that was presented (Delialioglu, 2012). The advantage of real-time feedback is such that instructors can walk struggling students through additional instruction for them to better understand the assignment. Furthermore, instructors can probe students who are competent in the assignment skills with additional work that can potentially challenge them further. Ideally, the flipped classroom allows for a completely individualized learning experience with each student so that instructors no longer worry about which students are bored and competent in the skills and which students are struggling and need to be brought along. This customization of learning is ideally student centered (Roach, 2014).

A common technique used in the flipped classroom is the video podcast (Bishop \& Verlenger, 2013). Podcasts are digital audio and/or video files that are created and made available through a downloaded access link. In a flipped classroom, podcasts can be created for specific course units or skill sets or for entire courses (Butt, 2014). In a meta-analysis of research on podcasts from 2004 to 2009, Heilesen (2010) found that students viewed podcasts as a genuine improvement to their learning environment and used podcasts as an additional tool to supplement their learning strategies.

Building on a goal to increase the efficiency of promoting scientific literacy in the academic setting, this researcher conducted a study using a 
pedagogical methodology in a manner that utilizes video podcasts to address some of the components outlined by Norris and Phillips. Specifically, the researcher wanted to ascertain if students perceive a video podcast and flipped classroom assignment useful in acquiring and implementing scientific literacy skills. Combining in-class assignments with video podcast homework is the most common flipped classroom technique. In this research, the in-class assignment was completed in a groupwork setting in which multiple students can work together to solve the questions in the assignment. While the students work together, the instructor is available to guide the discussion and reinforce the video podcast material.

\section{METHODS}

\section{Research Question}

This study examined the research question, "Do students perceive video podcast instructional videos as a useful tool for acquiring the skills of how to find and read a peer-reviewed journal article?" By examining this question, this researcher hopes to discover whether students benefitted from a flipped classroom experience to acquire scientific and information literacy skills. Acquiring scientific literacy skills will help students become more knowledgeable and critical of the world around them. They will be confident they can understand science information, make informed decisions after reviewing information, and participate in decision making. Students will also identify and provide feedback on the flipped classroom experience. As the field of pedagogy expands and the use of technology increases, studying the use of technology in a flipped classroom setting may lead to an evidence-based understanding of the effectiveness of this teaching tool.

\section{The Course and Assignment}

The course used in this research was a general education course at a state university in the eastern United States. The course is required for a major or minor in Sociology. Approximately eight sections are offered each semester. This course is a threecredit course and typically meets two times a week for 75 minutes for 15 weeks over the semester. Due to this being a general education course, students from a variety of disciplines are normally enrolled in this class. Data were gathered from four sections of this course in the spring of 2018. Course enrollment for all sections range between 25 and 50 students.

As part of the course requirements students must complete four group-work activities throughout the semester. These activities are completed in class, with the expectation that the activities reinforce concepts from the lectures and their textbook. This research is based on the fourth group work, which incorporated a "flipped classroom" exercise, i.e., in contrast to the first three group-work activities that did not use a flipped classroom methodology. For all four of the group-work activities students were randomly assigned to their group at the beginning of the class. Group size ranges from two to five students per group.

Prior to coming to class for the fourth groupwork activity, students were required to watch two video podcasts created by the author that explained how to find and how to read a peer-reviewed journal article. Each video podcast was approximately 20 minutes in length. After viewing the video podcasts, the students worked in their groups to complete a worksheet based on a journal article. In the worksheet students were required to respond to the following questions:

1. In your own words, what is the purpose of the study? What is research question the author(s) want to answer? (If it is not specifically stated, try to write the research question for them.)

2. In two to three sentences, why do the authors believe this is an important topic to study?

3. Summarize one study they use in their "background and significance" section. Why do they use this study? (How does it help their proposed research?)

4. Generally speaking, what do the results of their study find? What evidence do they find that supports their research question or thesis?

5. What is their conclusion or "take-away" points? What do they want us to know about what they found in their study?

6. What do they suggest are the limitations of their research? If not stated, can you think of anything they could have done better or different to test their research question? 


\section{Podcasts and Instrument}

The video podcasts were created using Screencast-O-Matic, which is a free program that allows the creating, editing, and sharing of recorded videos. Each video podcast was designed to capture the computer screens the students would see when they conducted a literature search. The video podcasts were created with their school website screen as the focus and a voice narration laid over it. Highlighted arrows guide the students through the video. Videos can be paused and replayed during the viewing. The video podcast How to Find a Peer Reviewed Journal Article was 19:45 minutes in length. The video podcast How to Read a Peer Reviewed Journal Article was 23:07 minutes in length. No students were identified in the four sections as needing accommodations with viewing or listening to the podcasts. However, close captioning could have been added to accommodate students if needed. The podcasts were uploaded to the "Announcements" section of D2L, the University's online education platform. D2L was the primary mode for students to access their grades, preview assignments, review grading rubrics, and download PowerPoint lectures and test-bank questions.

Two survey instruments were created for students to complete upon reviewing the video podcasts. The surveys were uploaded to D2L and students were given directions on how to access and complete the surveys. Completing the survey was not a graded element of the assignment but was included in the assignment instructions. Instructions for the survey stated:

After watching the podcast, please complete the following survey. Results from this survey will be used to determine the effectiveness of the podcast as an instructional tool for understanding how to find and read a peer-reviewed journal article. You may skip any question that you do not want to answer. Your responses are used only for understanding the teaching effectiveness of this assignment and are not part of any grade. Please choose answers that reflect your experience.

Each survey consisted of 15 items. The items were created using a five-point Likert scale ranging from Strongly Agree to Strongly Disagree (with a midpoint option of Neither Agree nor Disagree). Statements in the survey focused on the previous knowledge of skills (i.e., "I already knew how to find a Peer-Reviewed Journal Article"), current learned skills (i.e., "After watching this video I am confident I can complete the tasks of this assignment"), and future behavior (i.e., "This video taught me information I can use in my other classes"). Survey questions can be found in Appendix A.

\section{FINDINGS}

\section{Student Demographics}

The demographics from the four classes of the students participating in the course show $60 \%(\mathrm{~N}=$ $74)$ of students were Freshman, $27 \%(\mathrm{~N}=33)$ were Sophomores, $10 \%(\mathrm{~N}=12)$ were Juniors, and $4 \%$ $(\mathrm{N}=5)$ were Seniors.

An overwhelming majority of the students, $76 \%(\mathrm{~N}=94)$ were taking this course as a General Education Requirement for the school; 18\% (N $=22$ ) of the students were taking the course as a requirement for their major or minor; $2 \%(\mathrm{~N}=3)$ of the students were taking the course as an elective in their major or minor; and 3\% ( $\mathrm{N}=4)$ of the students were taking the course as a free elective.

\section{Finding a Peer-reviewed Journal Article}

Surveys were completed by 106 students across the four classes. Students who completed the survey answered all the questions in the survey and no missing data were encountered. Completion rates per class ranged from $73 \%$ to $84 \%$. The goal of the assignment was to teach scientific literacy by teaching the students how to find and read a peerreviewed journal article. The data show that $72 \%$ $(\mathrm{N}=76)$ of the students said they know how to find a peer-reviewed journal article. Nineteen percent of students agreed or strongly agreed that they did not know how to find an article, and $9 \%(\mathrm{~N}=10)$ neither agreed nor disagreed.

Students overwhelmingly agreed or strongly agreed $(89 \%, \mathrm{~N}=94)$ that the video podcast was helpful for them searching for peer-reviewed articles. After watching the video podcast students reported they strongly agreed/agreed $(92 \%, \mathrm{~N}=$ 98 ) that they were confident to complete the course assignment on deconstructing a peer-reviewed journal article. Only two students (1.8\%) disagreed 
that they were confident they could complete the assignment. Additionally, students found that the information that they learned in the video podcast would be helpful in other classes. Ninety percent $(\mathrm{N}=95)$ of the students agreed or strongly agreed that the video podcast would be helpful in other classes. Over half of the respondents, $53 \%(\mathrm{~N}=$ 56) strongly agreed that the information would be helpful, and over one third agreed it would be helpful $(37 \%, \mathrm{~N}=39)$.

The concept of the flipped classroom is for the students to acquire the background knowledge outside the classroom and come to class prepared to apply the learned material. This form of classroom is different from the traditional lecture and homework format, and students often struggle with the transition from being passive to active students in the classroom. The student responses demonstrated this when asked if they preferred to watch the videos on their own time. Only nine percent $(\mathrm{N}=10)$ of the students agreed or strongly agreed. However, 47\% $(\mathrm{N}=50)$ disagreed or strongly disagreed with watching the videos on their own time. Furthermore, it was nearly evenly split with $25 \%(\mathrm{~N}=27)$ of the students wanting the teacher to review the material in class and $25 \%(\mathrm{~N}$ $=28$ ) not wanting the review. The remaining $50 \%$ $(\mathrm{N}=51)$ were neutral on having the teacher review the material.

One can conclude from this analysis that the students felt they generally acquired specific skills in scientific literacy after watching this video podcast. Specifically, students strongly agreed or agreed $(95 \%, \mathrm{~N}=101)$ that they knew how to pick a search engine to look for scientific articles and that they knew how to indicate that they wanted only peer-reviewed articles in their search $(93 \%, \mathrm{~N}$ $=99$ ). Students also felt confident that they learned more complex skills with $95 \%(\mathrm{~N}=101)$ of the students strongly agreeing or agreeing they knew how to layer terms in the search bar and restrict the date range in the search $(93 \%, \mathrm{~N}=99)$.

\section{Reading a Peer-reviewed Journal Article}

The surveys were completed by 117 students in four Introductory Sociology classes. The students who completed the survey answered all the questions in the survey and no missing data were encountered. Completion rates per class ranged from $76 \%$ to $87 \%$ in each of the classes. Overall
$92 \%(\mathrm{~N}=79)$ of the students strongly agreed or agreed that overall the video podcast was helpful for them to learn how to read a peer-reviewed journal article. Only $27 \%(\mathrm{~N}=31)$ of the students agreed or strongly agreed that they did not know how to read a peer-reviewed journal article with $59 \%(\mathrm{~N}=70)$ of the students saying they had this skill. In acquiring the skills $15 \%(\mathrm{~N}=14)$ of the students indicated that they had to watch the video podcasts multiple times to learn the skills. Most students $(53 \%, \mathrm{~N}=64)$ preferred to watch the video podcasts on their own time. However, $39 \%(\mathrm{~N}=$ 46) strongly agreed or agreed that they would like the professor to review the material with them.

According to this analysis, students overwhelmingly acquired specific skills for scientific literacy through this video podcast. A significant majority of the students felt that they understood what information they would find in each section of a peer-reviewed research article $(91 \%, \mathrm{~N}=107)$ and that they knew how to use key words to find additional articles $(88 \%, \mathrm{~N}=103)$ and how to use the reference section to find additional articles on the topic $(94 \%, \mathrm{~N}=110)$. Additionally, students believed they could identify the research hypothesis $(88 \%, \mathrm{~N}=103)$ and the limitations of the study $(91 \%, \mathrm{~N}=107)$. A very large fraction of the students $(88 \%, \mathrm{~N}=99)$ strongly agreed or agreed that they could cite the article using APA format.

\section{DISCUSSION}

\section{Video Podcasts and Flipped Instruction}

The flipped classroom approach to teaching is designed to empower students to take a more active role in the classroom. To be active in the flipped classroom, students are typically required to complete some learning requirement prior to the class. The video podcast is often the homework assigned. In this study, the students overwhelming agreed that the video podcasts were helpful in completing the assignment of both finding and reading peer-reviewed journal articles. A small number of the students (15\%) utilized the opportunity to view the video podcasts multiple times to ensure they were competent in the skills and knowledge they would need to complete the in-class assignment.

Assigning video podcasts as required homework as essential for in-class activities was met with mixed responses from the students. A quarter 
of the students $(25 \%)$ preferred that the instructor review with them the material of how to find a peer-reviewed article, and over a third (39\%) preferred that the instructor review the material of how to read a peer-reviewed article with them in class. Empowering the students to view and review material outside of class and then engage with the acquired knowledge inside of class is still a relatively new concept compared to the passive learning strategies students have become accustom to; hence, this study shows that there is possibly some hesitation among some students in taking an active learning role without the instructor reviewing the material with them.

\section{Scientific Literacy Skills Acquired}

The results of this study found that most of the students claimed they both new how to find a peerreviewed journal article (97\%) and read a peerreviewed journal article (60\%). However, examples from class suggest this might not be accurate. While students surveys indicated that students felt they had the skills to pick an appropriate search engine, layer search terms, indicate peerreviewed material, and restrict the date range when searching for a peer-reviewed journal article, and while students generally felt equally confident that they could read articles and understand hypotheses and limitations, some students often struggled to answer the questions regarding these specific skills. In fact, some students even asked the instructor how to search on Google for articles, if they can use Wikipedia or the Bible as a source, and if they had to have their friends read the articles to make them "peer reviewed." In their classroom groups as the students worked through the assignment there was much discussion about how to identify the appropriate methods for peer review and what constitutes appropriate references. The discussions also focused on clearly identifying the research hypothesis of a given study, listing the variables of the study, and summarizing the conclusion. The students often called on the instructor to help them answer these specific questions.

\section{LIMITATIONS AND RECOMMENDATIONS}

There are several limitations to this study. First, most students indicated that they already had the skills that were being taught in the video podcast. The use of a pretest would have provided information of the base-line skills the students had. Since there was no pretest to see if this was the case, their self-report cannot be confirmed. Second, data collected were collected anonymously and more sophisticated analysis comparing STEM and non-STEM students, class standing, or other demographic factors cannot be completed. Finally, the assignment that the students were tasked to complete during class time was done as a group, so it is difficult to attribute the contribution of any individual's specific knowledge and skills gained from the video podcast.

The recommendations for continuing this research on the effectiveness of video podcast use for flipped classroom acquisition of skills should include graded pre- and posttest individual assignments. Additional variables, such as major and year of college, should also be included in the analysis.

Because scientific literacy is generally perceived as a skill only necessary in STEM related classes, the liberal arts has often ignored incorporating scientific literacy as applicable to instruction in, for example, the social sciences. However, the skills needed to perform a search for a peer-reviewed journal article, and the skills needed to read that article critically, are essential for all students, regardless if they are in STEM or non-STEM fields. Departments across all disciplines should be teaching students these skills or confirm that they have them. Hence data should be collected on students by degree major, which may help colleges understand if there is a discrepancy between departments in teaching these skills.

\section{CONCLUSION}

Norris and Phillips' meta-analysis outlined four definitions of scientific literacy in which each component was equally valuable. Distinguishing what is scientific data, understanding the risks and benefits of scientific research, participating in science related social issues, and thinking critically are all valuable skills. Acquiring skills is a key purpose of a college education and applying those skills to real-world issues should be the goal for all students. Higher education instructors can lead students to this outcome through innovative methodologies. Specifically, the goal of scientific literacy should align with the goal of higher education to create an informed and knowledgeable population.

Scientific literacy is a key skill for college students. Courses across multiple disciplines 
should devise strategies to test students' knowledge and application of these skills. Flipped classroom techniques provide useful tools for students to learn material outside of the classroom to be applied during course time. Video podcasts provide a formative tool for delivering a visual representation of how students can acquire skills for class assignments throughout their college career. 


\section{REFERENCES}

Abeysekera, L., \& Dawson, P. (2014). Motivation and cognitive load in the flipped classroom: Definition, rationale and a call for research. Higher Education Research \& Development, 34(1), 1-14. doi:10.1080/07294360.2014.934336

Bishop, J., \& Verlenger, M. (2013). The flipped classroom: A survey of the research. In 120th American Society of Engineering Education National Conference Proceedings, Atlanta, Georgia June 23-26, 2013. Retrieved from https:// peer.asee.org/22585

Butt, A. (2014). Student views on the use of a flipped classroom approach: Evidence from Australia. Business Education \& Accreditation, 6(1), 33-44.

Chen, H. L., \& Summers, K. L. (2015). Developing, using, and interacting in the flipped learning movement: Gaps among subject areas. The International Review of Research in Open and Distributed Learning, 16(3), 41-63. doi:10.19173/irrodl. v16i3.1975

Delialioglu, Ö. (2012). Student engagement in blended learning environments with lecture-based and problem-based instructional approaches. Journal of Educational Technology \& Society, 15(3), 310-322.

Heilesen, S. B. (2010). What is the academic efficacy of podcasting? Computers \& Education, 55(3), 1063-1068. doi:10.1016/j.compedu.2010.05.002

Holbrook, J., \& Rannikmae, M. (2007). The nature of science education for enhancing scientific literacy. International Journal of Science Education, 29(11), 1347-1362. doi:10.1080/09500690601007549

Horn, Mi. B. (2013) The transformational potential of flipped classrooms. Education Next, 13(3). Retrieved from https:// www.educationnext.org/the-transformational-potential-offlipped-classrooms/

McGeough, R., \& Rudick, C. K. (2018). "It was at the library; therefore it must be credible": Mapping patterns of undergraduate heuristic decision-making. Communication Education, 67(2), 165-184. doi:10.1080/03634523.2017.140 9899

National Research Council. (1996). National Science Education Standards. Washington, DC: The National Academies Press. doi:10.17226/4962

Norris, S. P., \& Phillips, L. M. (2003). How literacy in its fundamental sense is central to scientific literacy. Science Education, 87(2), 224-240. doi:10.1002/sce.10066
Park, T., Pearson, D., \& Richardson, G. B. (2017). Curriculum integration: Helping career and technical education students truly develop college and career readiness. Peabody Journal of Education, 92(2), 192-208. doi:10.1080/016195 6X.2017.1302213

Roach, T. (2014). Student perceptions toward flipped learning: New methods to increase interaction and active learning in economics. International Review of Economics Education, 17, 74-84. doi:10.1016/j.iree.2014.08.003

Smith, K. V., Loughran, J., Berry, A., \& Dimitrakopoulos, C. (2012). Developing scientific literacy in a primary school. International Journal of Science Education, 34(1), 127-152. doi:10.1080/09 500693.2011.565088

Stark, E., Kintz, S., Pestorious, C., \& Teriba, A. (2018). Assessment for learning: Using programmatic assessment requirements as an opportunity to develop information literacy and data skills in undergraduate students. Assessment \& Evaluation in Higher Education, 43(7), 1061-1068. doi:10.1080/02602938.2018.1432029

Tucker, B. (2014). The flipped classroom. EducationNext, 12(1). Retrieved from https://www.educationnext.org/the-flippedclassroom/

Yacoubian, H. (2018). Scientific literacy for democratic decisionmaking. International Journal of Science Education, 4(3), 308-327. doi:10.1080/09500693.2017.1420266 


\section{APPENDIX A}

Below is the list of statement in the on-line survey students were asked to complete. The response options included: Strongly Agree, Agree, Neither Agree nor Disagree, Disagree, and Strongly Disagree.

How to find a peer-reviewed journal article

- Overall this video was helpful to me in searching for a peer-reviewed journal article for class

- This video was the right length

- After watching this video I know what the professor means by a "peer-reviewed journal article"

- This video taught me information I can use in my other classes

- After watching this video I am confident I can complete the tasks of the assignment

- I prefer to watch a video on my own time

- I wish the professor would go over the information from the video in class

- Once I am on the search page I know where to find the indicator I must check to ensure I find peerreviewed research

- I understand the reason for layering my terms in the search bar

- I understand when to change the date range in the search bar

- I understand how to pick a search engine to look for an article

- The video moved too quickly through the information

- I needed to watch this video multiple times to understand the information

- I understand how to review the articles that are found when the search is complete

- I already knew how to find a peer-reviewed journal article before watching this video

How to read a peer-reviewed journal article

- Overall this video was helpful to me in reading a peer-reviewed journal article for class

- This video was the right length

- This video taught me information I can use in my other classes

- After watching this video I am confident I can complete the tasks of the assignment

- I prefer to watch a video on my own time

- I wish the professor would go over the information from the video in class

- The video moved too quickly through the information

- I needed to watch this video multiple times to understand the information

- I already knew how to read a peer-reviewed journal article before watching this video

- I understand what information I can find in each section of a peer-reviewed journal article

- I understand how to use the keywords to find additional articles

- I understand where to find the researchers hypothesis in a peer-reviewed journal article

- I understand where to find the limitations of the study in a peer-reviewed journal article

- I understand how to create an APA citation from the article(s) I review

- I know how to use the reference section of the article to help me find more articles on my topics 